\title{
APUNTES SOBRE PANAMÁ
}

\section{NOTES ON PANAMA}

\section{AUTOR}

\section{Sergio Hernández Aguilar}

Periodista y autor de varios artículos científicos y relevantes columnas de opinión.

shernandeza@hotmail.com

\section{RESUMEN}

Panamá posee una fuerte posición estratégica que carece de sustituto en el mundo. Se han propuesto muchos proyectos y obras para mejorar la calidad del Canal, algunos rechazados por estar EEUU detrás. Se han preparado campañas mediáticas que han llegado incluso a Hollywood.

\section{PALABRAS CLAVE}

EEUU - Panamá - Canal - Medios - Hollywood

\section{ABSTRACT}

Panama has a strong strategic position that has no substitute in the world. Have been proposed many projects and works to improve the quality of the canal, some being rejected by the U.S. behind. Media campaigns have been developed that have even Hollywood.

\section{KEY WORDS}

U.S. - Panama - Canal - Media - Hollywood 
REVISTA DE LA SEECI.

Hernández Aguilar, Sergio (2000): Apuntes sobre Panamá. № 6. Noviembre. Año IV. Páginas: 50-59.

ISSN: 1576-3420 DOI: http://dx.doi.org/10.15198/seeci.2000.6.50-59

\section{ÍNDICE}

1. Introducción

2. Conclusión

“... Y América y el hombre dignos sean"

José Martí

Este fin de año asistiremos a uno de los hechos más importantes en la historia reciente de América Latina: la devolución del canal de Panamá a sus legítimos dueños. En efecto, los acuerdos Torrijos-Carter (firmados en 1977) establecen que para el 31 de diciembre de 1999, el canal y todas las instalaciones adyacentes (la llamada zona del canal) deberán ser administradas por panameños. Este acuerdo deroga otro firmado en 1903 (tratado Hay-Bunau-Varilla) y que es el sustento legal de la permanencia norteamericana en Panamá. Antes de que eso ocurra deberíamos poner atención en algunos acontecimientos que pueden producirse en torno a este importante suceso.

Una vez pasadas las elecciones y conocido el próximo presidente de Panamá, se podría pensar que se avecina una ofensiva mediática por parte de los EEUU para crear un estado de opinión favorable a una nueva negociación de los mencionados acuerdos Torrijos-Carter. Una nueva versión más ventajosa para los intereses norteamericanos. El canal y la zona adyacente tienen una gran importancia tanto económica como geopolítica en el ámbito mundial. Más de un 10\% del comercio 
REVISTA DE LA SEECI.

Hernández Aguilar, Sergio (2000): Apuntes sobre Panamá. No 6. Noviembre.

Año IV. Páginas: 50-59.

ISSN: 1576-3420 DOI: http://dx.doi.org/10.15198/seeci.2000.6.50-59

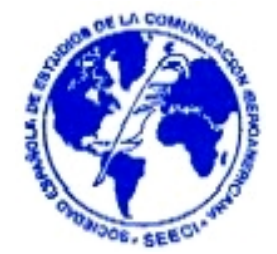

mundial utiliza el canal panameño y países como Nicaragua, Cuba, El Salvador, Ecuador y Perú dependen de esa vía para mover su comercio exterior. ${ }^{1}$

En cuanto a aspectos militares Panamá, muy a su pesar, ha representado para EEUU una suerte de portaviones en la cintura de América. Para no extender mucho estas notas simplemente recordaré que Panamá es una posición de privilegio desde el punto de vista de la geopolítica en América Latina. Esto que pareciera ser una afirmación peregrina no resulta tal si repasamos lo que el analista panameño Manuel F. Zárate nos dice al respecto:

"Así, la defensa nacional y seguridad interna del estado estuvieron garantizados por los EEUU a lo largo de toda nuestra historia republicana, solamente que basándose en su doctrina de Seguridad Nacional y no en los intereses panameños"12

Tanto el valor del canal para la economía como su importancia en lo militar son temas ampliamente conocidos. Sin embargo, yo creo que el canal tiene, además, una carga emocional para Panamá y para América Latina considerable. Si la derecha europea (y mundial) tuvo su "big party" cuando se derribó el muro de Berlín, la Izquierda Latinoamericana (y otros sectores de la población) tendrán la suya en el momento en que el canal sea administrado por panameños.

Se dice que como alternativa al Canal de Panamá, los EEUU, tienen algunas opciones más o menos viables. Las dos más importantes se basaban en la idea de construir otro canal en la misma zona de América. Una vía se marca por Nicaragua aprovechando sus lagos. El gobierno actual es visto como proclive a la propuesta.

\footnotetext{
$1 \quad$ Fernández Penit, Sara: "El canal de Panamá en la globalización de la economía mundial" en EL CANAL DE PANAMÁ EN EL SIGLO XXI, Encuentro académico internacional sobre el Canal de Panamá, Universidad de Panamá, 1998. Pág. 43.

2 Zárate, Manuel F.: "Reversión y Seguridad del Canal" en EL CANAL DE PANAMÁ EN EL SIGLO XXI. Encuentro académico internacional sobre el Canal de Panamá. Universidad de Panamá, 1998, Pág. 217.
} 
REVISTA DE LA SEECI.

Hernández Aguilar, Sergio (2000): Apuntes sobre Panamá. № 6. Noviembre.

Año IV. Páginas: 50-59.

ISSN: 1576-3420 DOI: http://dx.doi.org/10.15198/seeci.2000.6.50-59

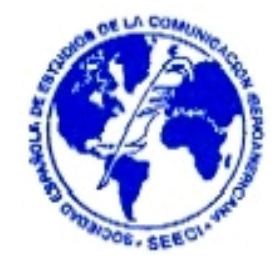

Ciertamente Arnoldo Alemán ha mostrado su disposición a esta clase de iniciativas (y otras aún peores). No obstante, la situación que se vive actualmente en Nicaragua obliga a suponer que no hay condiciones sociales para construir un nuevo canal en ese país. Además, es necesario incluir en cualquier análisis de Nicaragua a una fuerza que aún representa a una parte importante de la población: el Frente Sandinista de Liberación Nacional. Muy torcidas tendrían que estar las cosas en Nicaragua como para que los sandinistas aprobaran la construcción de una obra de tal calibre. Por tato, es dable pensar que es poco probable el establecimiento del proyecto canalero, por utilizar términos empleados por los panameños, en tierras nicaraguenses. La otra posibilidad sería en México, en concreto en el istmo de Tehuantepec. Después de una primera intención sostenida largo tiempo, y que pretendía hacer otro canal, la posibilidad que va ganando cuerpo es la construcción de un ferrocarril transístmico.

Desconozco la situación actual exacta de tamaña obra pero es una alternativa a largo plazo y con sus reservas. Acometer una labor de esa magnitud requiere de varias disposiciones importantes. Una es la privatización tanto del puerto de Salinacruz en el océano Atlántico como el de Coatzacoalcos en el Pacífico. Por su parte el sistema mexicano de transporte por tres casi concluye su proceso de desincorporación (eufemismo utilizado para suavizar el término "privatizar"). Otro paso es propiamente la construcción de la línea de ferrocarril contemplado el impacto tanto ambiental como social de su implantación.

Existen iniciativas para compensar a las comunidades afectadas directamente pero son de escasa repercusión y es de esperar que exista contestación social de relevancia. Sin mencionar que algunas de las regiones por las que transcurre la vía férrea son territorio de operación de grupos guerrilleros. Adicionalmente debe contemplarse la respuesta del resto de la nación ante una situación que produce la línea del ferrocarril: Divide al país en dos. Por lo anterior es imaginable que el 
REVISTA DE LA SEECI.

Hernández Aguilar, Sergio (2000): Apuntes sobre Panamá. № 6. Noviembre.

Año IV. Páginas: 50-59.

ISSN: 1576-3420 DOI: http://dx.doi.org/10.15198/seeci.2000.6.50-59

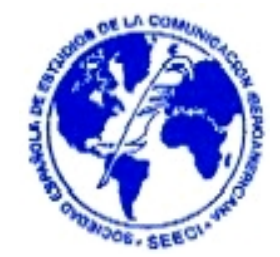

funcionamiento del tren interoceánico tardará en producirse varios años. Además de no ser una alternativa muy sustanciosa al canal de Panamá pues se elevan los costes de transportación cuantiosamente al tener que descargarse los productos del barco al tren y después de transportados por tierra al otro extremo del país, nuevamente colocados en otro barco. Son gastos considerables. En ninguna de estas dos opciones es previsible que se incluya un apartado militar que permita al gobierno de EEUU el despliegue de sus soldados en la zona. Cabe señalar que se ha manejado la existencia de una comisión de estudios de alternativas al canal. Esta comisión fue trilateral (Panamá, EEUU y Japón) y lo que en realidad estudió fue las opciones del propio territorio panameño ante la necesidad de contar con un canal que permita el paso de barcos de gran tonelaje (se habla de barcos con capacidad de 150.000 DWT, Toneladas de peso muerto, y hasta de 250.000). La comisión determinó que se puede ampliar la capacidad actual del canal construyendo un Tercer juego de Esclusas. Es decir, no se plantea la salida de EEUU de la zona. Lo anterior invita a pensar que el gobierno de los EEUU intentará por todos los medios aplazar su salida del canal.

Uno de esos intentos fue la pretensión de establecer el Centro Multilateral Antidrogas (CMA) en la base Howard del canal de Panamá. Este proyecto, que los gobiernos de EEUU y Panamá mantuvieron en secreto, fue motivo de polémica internacional y desmentidos, pues se trataba de crear una fuerza militar multinacional que tendría como objetivo la lucha contra el narcotráfico. Países como Brasil, México y Colombia se desmarcaron públicamente del proyecto dejando a EEUU en el afán.

El actual presidente de Panamá, Ernesto Pérez Balladares, perdió una consulta popular hecha en 1998, y que intentaba cambiar la constitución permitiendo la reelección presidencial. Según reportes proporcionados por el MONADESO, 
REVISTA DE LA SEECI.

Hernández Aguilar, Sergio (2000): Apuntes sobre Panamá. № 6. Noviembre. Año IV. Páginas: 50-59.

ISSN: 1576-3420 DOI: http://dx.doi.org/10.15198/seeci.2000.6.50-59

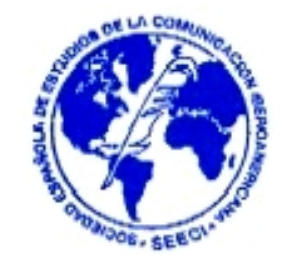

"el repudio popular a Pérez Balladares también es consecuencia de su política de negociar con EEUU la prolongación de bases militares norteamericanas después del 2000 disfrazadas como Centro Multilateral Antidrogas". ${ }^{3}$

Felizmente el CMA quedó desechado por ambos gobiernos.

Otro hecho importante reciente nos da pistas de las intenciones de EEUU en la devolución del canal. Lo publica un medio de comunicación panameño, se trata del periódico El Panamá América: dos políticos importantes, líderes tanto del senado como de la cámara de diputados de EEUU, le envían una carta a Clinton urgiéndolo para que "Ordene al Departamento de Defensa demore la entrega de la base aérea de Howard y renegocie con el nuevo gobierno la permanencia de las tropas en Panamá"4t

Finalmente, es de señalar que el más vigente argumento esgrimido por los EEUU para no abandonar las bases en Panamá antes del 2000 es que, esas bases están contaminadas. En el número 1 de Soberanía, revista electrónica del MONADESO, se refiere un artículo aparecido en el Washington Post, en el que se cita a voceros del Departamento de Defensa para afirmar que sería imposible limpiar las bases sin causar graves daños ecológicos en la zona. Pareciera un chantaje para que se permita su permanencia en las bases en tanto se limpian. Proceso que puede tomar un par de años. Entre los problemas de contaminación que presentan las bases se señala que aún contienen grandes cantidades de explosivos sin detonar y los residuos químicos que se utilizan en operativos militares.

\footnotetext{
3 Movimiento Nacional por la Defensa de la Soberanía (MONADESO). Boletín Sobernía \#6, versión electrónica.

$4 \quad$ El Panamá América, nota firmada por Henry Raimont y publicada el 8 de marzo de 1999. Versión electrónica.
} 
REVISTA DE LA SEECI.

Hernández Aguilar, Sergio (2000): Apuntes sobre Panamá. № 6. Noviembre.

Año IV. Páginas: 50-59.

ISSN: 1576-3420 DOI: http://dx.doi.org/10.15198/seeci.2000.6.50-59

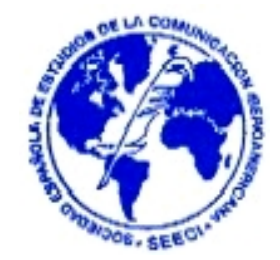

Para enfrentar este asunto, los gobiernos de EEUU y Panamá crearon una comisión de estudio. EEUU ha expresado que no limpiará las bases debido al alto coste de tal operación. Ello para obtener más tiempo de permanencia. Es lamentable comprobar lo certera que es la frase que reza aquello de "lo que no se publica no existe". Para cuando redacto estas notas, la prensa española no ha dado una mínima atención a las elecciones panameñas de este 1999. Ocupada como está en otras batallas ofrece escasa información de un proceso electoral sin incidentes ni muertos. En lo que queda de año la agenda de América Latina tiene pendientes importantes acontecimientos: elecciones generales en octubre en Uruguay y Argentina, Guatemala en Noviembre y Chile en diciembre. Habrá que agregar el trascendente año político que se vive en México previo a las elecciones del 2000. Todas estas citas propician una amplia movilización social que se debe tomar en cuenta para montar cualquier estrategia en Latinoamérica en el presente año.

Suponiendo que la ocupación militar, una nueva invasión, es una posibilidad descartada (por contraproducente en estos momentos, no por otros motivos; no hay Noriega que la justifique) en la agenda del gobierno de EEUU para conservar la hegemonía en Panamá, en válido suponer que se intentarán otras vías. ¿Cuáles podrían ser? Como se ha dicho, cuando se malogró el proyecto del CMA el gobierno de Panamá estaba de acuerdo en renegociar el asunto de la presencia norteamericana en la zona. Esto es, existen indicios para suponer que el gobierno de IOS EEUU lleva encaminadas las conversaciones de renegociación con el actual gobierno, y muy posiblemente con la presidenta electa.

(Una vez perdida la posibilidad de ofrendar a los panameños y la comunidad internacional una versión nueva de los acuerdos Torrijos-Carter, esta vez con una ligera variante: Torrijos-Clinto). Existe el antecedente, mencionado más arriba, del referéndum que perdió el PRD, así que se requiere de una estrategia mayor para lograr persuadir tanto a la opinión pública panameña como a la internacional. 
REVISTA DE LA SEECI.

Hernández Aguilar, Sergio (2000): Apuntes sobre Panamá. № 6. Noviembre.

Año IV. Páginas: 50-59.

ISSN: 1576-3420 DOI: http://dx.doi.org/10.15198/seeci.2000.6.50-59

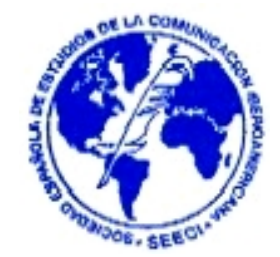

Pudiera ser, y esto ya en el resbaladizo territorio de las especulaciones, que se estuviera preparando una campaña mediática. O Hollywood al rescate. Una pista de ello es la película que actualmente se rueda sobre Manuel Antonio Noriega en EEUU. En su edición del 25 de abril de 1999, el periódico El País publica en una sección dedicada a chismorreos ("Gente" firmada por Karmentxu Marín5 5 ), que Noriega se encuentra muy enfadado porque no le pidieron su opinión sobre la película y "teme no quedar muy bien parado". La nota se recrea en decir que Noriega es "traficante de drogas", "extorsionador", y que está prisionero en Miami. La periodista se permite la licencia de decir que quizá la molestia de Noriega se deba a que la película Noriega, favorito de Dios tal vez critique "las atrocidades que hizo mientras estaba en el poder, como decapitar a un rival, o lanzar a un cura disidente desde un helicóptero". Pero no ofrece ninguna pista sobre el argumento real de la película.

Al margen de las críticas que se puedan hacer a la periodista por su ligereza informativa, me interesa resaltar el hecho mismo de la aparición tanto de la película como de la misma nota en estos días. ¿Por qué ahora? En las condiciones en las que está el general Noriega resulta inofensivo. ¿Aporta la película información, elementos de análisis o datos que permitan entender la situación de Panamá en 1989 y justifiquen la invasión? ¿Tendrá interés comercial una película sobre su vida?

No apelo a la teoría de la conspiración pero pudiera ser que la película forme parte, como se dijo más arriba, de una estrategia diseñada para crear un estado de opinión favorable a replantearse la salida de las fuerzas armadas norteamericanas de la zona del canal de Panamá en el año 2000. Esta campaña podría confeccionarse con artículos de prensa, películas, programas de radio y televisión, ensayos, congresos, declaraciones y hasta canciones y obras de teatro. Una campaña dirigida tanto a la opinión pública norteamericana como a la panameña e internacional, recurriendo a distintos temas en cada caso. Los temas podrían ser entre otros lo corruptible de los

Karmentxu, Marín, Gente, El País, 25 de abril de 1999. Edición electrónica. 
REVISTA DE LA SEECI.

Hernández Aguilar, Sergio (2000): Apuntes sobre Panamá. № 6. Noviembre.

Año IV. Páginas: 50-59.

ISSN: 1576-3420 DOI: http://dx.doi.org/10.15198/seeci.2000.6.50-59

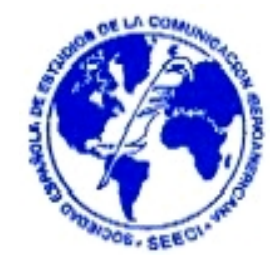

ejércitos del tercer mundo, la falta de eficacia como administradores de los panameños (y/o de los habitantes de América Latina en general), la importancia del canal para el comercio mundial, el peligro del narcotráfico en América Latina, el talante subversivo del presidente de Venezuela, Hugo Chávez, el riesgo para el canal ante la existencia de grupos guerrilleros poderosos en la vecina Colombia, al fragilidad de la democracia en Panamá y otros. Todo esto con el fin de invocar la cláusula que permite la presencia militar de EEUU en Panamá después del 2000 (Llamada reserva Nunn).

Quizá pudiera parecer excesiva la idea, sin embargo, la realidad comienza a darle sustento: el 5 de mayo de 1999 en la ciudad norteamericana de Atlanta, se llevó a cabo una conferencia titulada "Transparencia para el crecimiento de las Américas". Esta actividad fue organizada por líderes políticos y financieros tanto de EEUU como latinoamericanos. "La corrupción es una de las principales amenazas para la democracia, el crecimiento y la igualdad" ${ }^{6}$ se menciona en algún momento de la conferencia. Asimismo, se señala a la ciudad de Panamá como una en las que las tasas de homicidios se han incrementado entre tres y cuatro veces.

Seguramente vendrán más actividades como esa. Coincido con Marco A. Gandásegui ${ }^{7}$ al creer que, quizá, hoy una de las tareas del pueblo y del gobierno de Panamá es la preparación de unas Fuerzas Armadas que le permitan proteger el canal, cumplir los acuerdos Torrijos-Carter y amputar toda excusa que justifique la presencia de tropas norteamericanas en suelo panameño. que no se confundan los antimilitaristas, no se trata de hacer un canto a las armas. Es una necesidad de primer orden. Gandásegui da mayor cuerpo a esta idea, propone que:

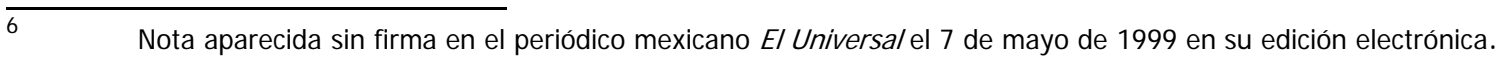

7 Gandásegui, Marco A. (1998): La democracia en Panamá. CELA, 2ª Edición. Panamá. Pág. 240. Para entender lo que ocurre en Panamá este libro resulta indispensable.
} 
REVISTA DE LA SEECI.

Hernández Aguilar, Sergio (2000): Apuntes sobre Panamá. № 6. Noviembre. Año IV. Páginas: 50-59.

ISSN: 1576-3420 DOI: http://dx.doi.org/10.15198/seeci.2000.6.50-59

"La República de Panamá tendría que crear una institución académica con el fin de formar a los oficiales que servirían en la defensa de la soberanía, en la protección del territorio nacional, así como la defensa del Canal de Panamán".

Añade que esa institución tendría que ser dirigida por panameños civiles. Ojalá que el pueblo panameño en su conjunto asuma la responsabilidad del momento. Es deseable que comprenda la situación, que se dé cuenta de que está ante la posibilidad, por primera vez en su historia, de ser un país sin tutela. Y lo más duro: que venza ese demonio terrible que el viejo maestro Fromm llamó el miedo a la libertad.

En un momento en el que se dan algunos procesos de descolonización, recuérdese que le próximo mes de diciembre Portugal devolverá Macao a China, país que recuperó Hong Kong de manos inglesas hace unos meses, la devolución del Canal de Panamá se antoja posible. No más Escuelas de las Américas, Comandos Sur o bases Howard en territorio panameño. Utilizando el habla popular se puede decir que por la cuenta que le trae, esta labor de recuperación debería ser asumida por toda América Latina. No ya con la creación de una fuerza militar multinacional pues eso abriría las puertas a la participación norteamericana, sino con iniciativas políticas de otro tipo.

Al final este es un lance, como tantos otros en curso, por la dignidad. Pero no solamente la de Panamá, sino la de toda América Latina. Quizá el siguiente paso sea Guantánamo (otro de los temores de EEUU), pero eso ya es otro cantar. 